\title{
Museus e seus arquivos: em busca de fontes para estudar os públicos
}

\author{
Museums and their archives: in search of sources \\ for researching audiences
}

\section{Luciana Sepúlveda Köptcke}

Pesquisadora e coordenadora de Educação, Cultura e Saúde/Diretoria Regional de Brasília/Fundação

Oswaldo Cruz.

Fundação Oswaldo Cruz/Direb Av. L3 Norte, Campus Universitário Darcy Ribeiro

Gleba A, SG 10, Asa Norte 70904-970 - Brasília - DF - Brasil Isk@fiocruz.br

\section{Marcele Regina}

Nogueira Pereira

Coordenadora de Museologia Social e Educação/Departamento de Processos Museais/Instituto Brasileiro de Museus.

Ed. Monte Carlo, apto.142 914 Norte

70790-160 - Brasília - DF - Brasil marcellepereira07@gmail.com
KÖPTCKE, Luciana Sepúlveda; PEREIRA, Marcele Regina Nogueira. Museus e seus arquivos: em busca de fontes para estudar os públicos. História, Ciências, Saúde - Manguinhos, Rio de Janeiro, v.17, n.3, jul.-set. 2010, p.809-828.

\section{Resumo}

Aborda a relevância dos arquivos históricos dos museus como fontes documentais para o desenvolvimento de estudos sobre os públicos. Analisa o processo de construção do conhecimento sobre a relação dos museus com os seus diversos visitantes e usuários, contextualizando o surgimento dos públicos como categoria de entendimento e objeto de estudo nas ciências sociais. Apresenta, como importante subsídio para as pesquisas nesta temática, o Guia de fontes primárias: o Museu Nacional seu público no século XIX e no início do XX, elaborado por Luciana Sepúlveda Köptcke e Marcelle Pereira. O guia de fontes consiste em ferramenta de orientação capaz de expandir o significado dos fundos documentais, revelando a natureza e o grau de importância atribuídos aos diferentes públicos pela instituição.

Palavras-chave: estudos de público; Museu Nacional do Rio de Janeiro; guia de fontes; Brasil.

\section{Abstract}

The article explores to what extent historical archives at museums may serve as documental sources in devel oping audience research. It analyzes the process by which we construct our knowledge of the relation between museums and their different visitors and also contextualizes the emergence of 'audience' as a category and object of study by the social sciences. The article presents Luciana Sepúlveda Köptcke and M arcelle Pereira's Guia de fontes primárias: o Museu Nacional - seu público no século XIX e no início do XX (Guide of primary sources: the National Museum - its audience in the nineteenth and early twentieth centuries), a valuable research tool that can enhancethe significance of documental fonds and reveal thenature and import assigned to different audiences by theseinstitutions.

Keywords: audience studies; National Museum of Rio de Janeiro; source guide; Brazil. 


\section{A relação dos museus com os públicos e a construção de um novo campo de estudo}

Os museus e, antes deles, as coleções e gabinetes em voga na Europa do século XVI, se caracterizavam como espaços onde se pressupunham não só a reunião, conservação, organização de objetos e o estudo feito a partir da sua observação, mas também a sua exposição ao olhar de terceiros. A organização das coleções obedecia a uma lógica de ressignificação normatizada e discutida publicamente em manuais e catálogos. $\mathrm{O}$ ato de reunir objetos acompanhava o projeto intelectual em curso e acordava prestígio social a colecionadores e admiradores das coleções, que partilhavam a construção de uma nova gramática para decodificar a natureza, a história, a modernidade (Pomian, 1987; Köptcke, 2005).

No século XVII os visitantes das coleções, gabinetes e gal erias integravam redes de sociabilidade. Cabia aos colecionadores regulamentar o acesso a seus gabinetes revelando um pensamento coletivo sobre os visitantes e públicos dos museus e coleções. Elias Ashmole, por exemplo, condicionou a doação de sua coleção à instalação da mesma em prédio próprio da Universidade de Oxford, garantindo o acesso aos estudantes.

A ideia de ampliar o acesso aos museus a outros segmentos da sociedade, com finalidades educativas, motivou a abertura das coleções privadas de reis e nobres à visitação de público não especialista, o que configurou um verdadeiro movimento cultural. Aflora a preocupação com a divulgação dos conhecimentos, que rapidamente se acumulam e multiplicam no bojo de 'revoluções' do pensamento científico. No âmbito do projeto das monarquias esclarecidas, o Museu Britânico, fruto de iniciativa parlamentar, foi o primeiro museu nacional criado pelo poder público (1753). Ainda durante o século XVIII, a exemplo do Museu de São Petersburgo, inaugurado em 1714, foram abertos o Museu Pio Clementino do Vaticano, a Galeria dos Ofícios, em Veneza, o Museu do Capitólio, em Roma, e o Belvedere, em Dresden (Poulot, 2000).

O Jardin des Plantes francês passa, em 1793, do domínio privado e real ao domínio público e republicano, tornando-se Muséum National d'Histoire Naturelle. O projeto jacobino previa instaurar na França instituições de instrução controladas pelo poder público. No mesmo período, o Palácio do Louvre torna-se museu nacional e não apenas é franqueado o acesso às coleções (embora com restrições de dia e horário), como o museu se institui como guardião de um patrimônio comum, associando o usufruto de seu acervo ao exercício da cidadania republicana. Esse caráter público e a dimensão educacional constituirão eixos estruturantes da criação dos museus nos países sul-americanos, no século seguinte (Lopes, 2003).

No decorrer do século XIX, o museu firmou-se como arena política, espaço de construção da memória coletiva e de formação de uma identidade nacional, de sociabilidade e de lazer ilustrado. Seus públicos eram diversos e numerosos. Curiosos, pesquisadores, educadores, filósofos e políticos registravam observações sobre as práticas de visita a tais espaços em cartas, textos literários, diários de viagem, artigos em periódicos. Além disso, existia o registro institucional, encontrado nos relatórios internos, regulamentos e recomendações. A leitura desses documentos que descreviam os visitantes e seus comportamentos, bem como a leitura das considerações normativas e críticas sobre os devidos e legítimos usos dos museus que ali se insinuavam, indica posições por vezes divergentes, como atesta o Florilégio reunido por Galard (1993) sobre o Louvre, mas sustenta o pressuposto de que não há museu sem públicos e sem a representação que deles se faz . 
A criação dos gran des museus nacionais europeus e americanos reflete o reconhecimento da natureza pública dessas instituições e valoriza, como componentes de sua missão, a pesquisa e a instrução da sociedade. Esse modo de perceber o museu ocasionou novas exigências de gestão. Implantou-se o registro sobre as atividades dos museus nas publicações, anualmente distribuídas para cientistas e para instituições análogas. Fomentou-se o intercâmbio entre pesquisadores. Valorizaram-se a riqueza e amplitude das coleções. Além disso, foi sistematizado o registro de presença nos livros de visitantes, de forma a permitir o acompanhamento e a análise do fluxo de visitas por dia e, algumas vezes, precisar o perfil dos visitantes (escolares, pesquisadores, professores, homens, mulheres e crianças). Os Livros de Ouro documentavam a presença de personagens ilustres na instituição. Os livros de controle de empréstimo de objetos ou coleções, as cartas documentando tais solicitações e as respostas da instituição pontuavam a rotina administrativa e adensavam os relatórios de circulação limitada.

Embora se percebam a prática de registro ea circulação de informações sobre os visitantes como atos constitutivos da própria essência do museu e das coleções, os registros de sua presença, seu perfil e sua opinião permaneciam formalmente desconectados das decisões internas da instituição, ainda muito distantes da avaliação por parte de visitantes e não visitantes, a que almejam os atuais estudos de público e as avaliações das exposições e da ação educativa.

O primeiro registro de estudo formal sobre visitantes de museu data do final do século XIX, na Inglaterra. Henry Hugh Higgins, curador do Museu de Liverpool, dedicou a primeira parte da publicação Museums of natural history aos visitantes do museu (Higgins, 1884; MacManus, 1997). No entanto, a proposta de avaliar a capacidade de os museus informarem e instruírem um público heterogêneo surge nos Estados Unidos, no início do século XX, como consequência da importância acordada a estas instituições no projeto de extensão da educação para diferentes segmentos sociais. $O$ interesse em explicar como as pessoas aprendem (ou por que não aprendem) seria o pano de fundo para a realização de pesquisas no campo da psicologia, nas quais se debate a importância de observar empiricamenteo comportamento humano diante de estímulos externos. ${ }^{1}$ Nesse cenário, Benjamin Gilman publicou, em 1916, trabal ho pioneiro sobre a fadiga museal, revelando que o interesse do visitante pel os módulos expositivos decresce ao longo da visita. Utilizando registros fotográficos de comportamentos, como o direcionamento da atenção visual, Gilman relacionou o decréscimo de atenção e interesse e o tempo passado na exposição à pobreza do design dos exhibits. Nos anos seguintes, precisamente nas décadas de 1920 e 1930, estudos sobre o comportamento durante visita aos museus ganharam força nos Estados Unidos, no âmbito da psicologia behaviorista (Robinson, 1928; Melton, 1933) e com o apoio da Associação Americana de Museus (AAM). Tais estudos trouxeram implicações para a gestão dos museus que deveriam considerar necessidades e características dos públicos na concepção de exposições, visando à efetividade em seus propósitos educativos. A psicologia norte-americana contribuiu para o campo da educação e dos estudos de público nos museus, inaugurando a linha de pesquisa sobre a compreensão das condições de apropriação museal a partir de atributos pessoais (dos visitantes), ambientais (das exposições) e sociais, ou da interação entre essas três abordagens (Falk, Dierking, 1992; Davey, 2005). Cabe lembrar que, na primeira metade do século XX, o uso da avaliação como 
prática estruturada migra da educação escolar - em que era empregada na análise das competências e conhecimentos dos al unos - para os museus, nos quais era utilizada como avaliação de um programa educacional em que o foco eram as exposições como fatores de estímulos mais ou menos adequados para modificar comportamentos e facilitar a aquisição de conhecimentos (Tyler, 1949).

No Brasil encontram-se dados quantitativos sobre visitantes de museus no início do século passado. A Diretoria Geral de Estatística, órgão que antecedeu o Instituto Brasileiro de Geografia e Estatística (IBGE), publicou, no primeiro Anuário estatístico do Brasil, dados sobre a cultura e, mais precisamente, sobre oferta de museus e o número de visitantes por mês e por ano, no período entre 1908 e 1912 (Köptcke, Pereira, 2002). Os dados eram fornecidos pelos museus, que deveriam prestar contas de suas atividades em relatórios anuais ao ministério ou secretaria a que fossem subordinados. Não temos conhecimento do registro sistemático de outros dados sobre visitantes dos museus brasileiros no período em questão, além dos dados apresentados pelas instituições museais em seus relatórios de gestão ou nos depoimentos de cronistas, muitos dos quais viajantes e memorialistas (Oliveira, 2002-2003). Ainda não identificamos registros de avaliações de exposições no Brasil, no início do século, como os que foram feitos em trabalhos norteamericanos.

No decorrer da segunda metade do século, os profissionais das instituições museais começaram a dedicar maior interesse a esse tema e a realizar estudos de público em suas instituições. $\mathrm{Na}$ academia se observa a diversificação dos campos disciplinares, cujos profissionais passaram a se interessar pelos públicos de museus: além da psicologia, da sociologia e da antropologia, do campo dos estudos sobre educação formal e não formal, a teoria da comunicação, a arquitetura e cursos de turismo e administração passam a produzir monografias, dissertações e teses com foco nos visitantes dos museus. Na França, por exemplo, a partir do pós-guerra, a retórica sobre a democratização da cultura, difundida por Malraux, levou o Estado francês a buscar evidências científicas sobre os efeitos das políticas públicas no setor cultural, e uma série de pesquisas e estudos ganhou espaço no campo das ciências sociais, entre os quais o célebre trabal ho de Bourdieu e Darbel, 0 amor pela arte: os museus de arte europeus e seu público (1969).

Pesquisas e avaliações no campo museal surgiram e se desenvolveram diante do aparecimento de um "outro conceito de museu que apontou novas perspectivas para abordar o discurso expositivo, o papel do público e a consideração de sua existência no desenho das exposições"2 (Asensio, Pol, s.d., p.2). Elas discriminam três fases dos estudos de público. A primeira seria a dos estudos anedóticos, em que predominam interesses particulares isolados, ausência de plano de trabalho, de metodologia e de sistematização. A segunda, designada estudos ingênuos, apresenta alguma sistematização e pessoal 'interessado', dedicado parcialmente à atividade. Finalmente, a terceira fase seria aquela dos estudos sistemáticos, caracterizados pelo acúmulo de experiências que compõem um corpo de conhecimento, com técnicas e quadros de análise variados e pessoal especializado, que se dedica especificamente à atividade. $\mathrm{O}$ autor classifica a atividade conforme os níveis de especial ização e institucional ização al cançados, uma entre várias possi bilidades de organizar o desenvolvimento dessas práticas no campo museal. 
Entre 1970 e 1980 são criados fóruns específicos de discussão e associações como a Visitors Studies Association (nos anos 1970). Nota-sea presença regular do tema em congressos e seminários, o aumento de publicações especializadas, como o International Laboratory for Visitor Studies Review (ILVS Review), o Journal of Visitor Behavior, e preocupação em institucionalizar e regulamentar o campo com a oferta de formação continuada para a avaliação em museus, principalmente nos Estados Unidos.

A afirmação da prática avaliativa reflete mudanças no ambiente dos museus, seguindo o movimento que toma forma a partir dos anos 1930 eindicando novos modos de aproximação entre a instituição e seus públicos. Isso ocorreu sobretudo nos Estados Unidos e na Europa, onde manifestações populares, acirradas após os acontecimentos de maio de 1968, permitiram a concretização de outra relação entre museu e sociedade, nos anos 1980 (Valente, 2009). O período entre a segunda metade da década de 1980 e a seguinte pontua a consolidação do campo nos Estados Unidos e na Europa, enquanto no Brasil observa-se a produção de estudos, dissertações e artigos ${ }^{3}$, com vistas a conhecer as práticas sociais relacionadas aos museus, mas também a levantar dados que orientassem decisões sobre investimentos e políticas públicas.

Cabe lembrar que, cada vez mais, museus passaram a partilhar financiamentos públicos e privados com outras instituições e encontravam-se inseridos em duas lógicas diferentes e nem sempre complementares: uma de mercado, da indústria cultural, e uma de legitimidade social. Nesse contexto, a pesquisa de público tornou-se peça estratégica para a negociação de fundos e para a conquista de credibilidade junto à sociedade (Köptcke, 2003).

O interesse em conhecer ou sistematizar a reflexão sobre os públicos dos museus está estreitamente relacionado às expectativas da sociedade quanto à missão de tais instituições. Público será compreendido, neste texto, como uma construção cuja natureza propomos discutir nas linhas seguintes. Encontram-se estas designações para a palavra:

7. O povo em geral; 8. Conjunto de pessoas que leem, veem ou ouvem uma obra literária, dramática, musical, etc. ou ainda 9. Conjunto de pessoas queassistem efetivamentea um espetáculo ...: assistência. O uso corrente do termo como um conjunto físico, deindivíduos queassistem a um espetáculo, visitam um museu, ... leem determinado jornal tem como sinônimos designações como espectadores, consumidores, usuários, leitores, ouvintes, telespectadores, etc. (Holanda, 1975, p.1165).

Para Teixeira Coel ho (1997), 'público' se deveria diferenciar da ideia demassa ou multidão e remeter ao conjunto de pessoas que não apenas praticam uma atividade determinada, mas também, diante dela, assumem um mesmo tipo de comportamento, sobre ela expressam opiniões e juízos de valor consideravelmente convergentes e dela extraem sensações e sentimentos análogos.

Pesquisas no campo da cultura (Bourdieu, Darbel, 2003; Donnat, Cogneau, 1990) sugerem que, de fato, ser público de alguma atividade cultural constitui um fenômeno particular da vida coletiva, diferente de fazer parte da multidão que se forma aleatoriamente ou de ser membro de uma associação, como um clube de xadrez ou uma escola de música (Moutchouris, 2003). No entanto, a observação das práticas e dos praticantes da cultura evidenciou não se tratar de um público único, homogêneo, com comportamentos, expectativas ou atitudes idênticas e permanentes ao longo do tempo (Becker, 1988; Lahire, 2004). 
É necessário utilizar o termo no plural e considerar a miríade de categorias identificadas pelos estudos, como no caso dos museus: público familiar, cativo, espontâneo, potencial, neófito, habitué, especial, turistas, de vizinhança, escolar, não público ${ }^{4}$, entre tantos outros. A perspectiva da história social da cultura ou da sociologia dos processos culturais entende que o público não é um grupo construído de uma vez por todas, mas um organismo vivo que se forma e se desfaz, constituindo-se de grupos sociais diferentes, segundo as convenções estáticas partilhadas entre produtores e consumidores de arte em determinado período (Becker, 1974, 1988), a exemplo do público de jazz nos Estados Unidos ou mesmo do samba ou do funk no Brasil. Os processos respon sáveis pel a formação de um público resultam da interação entre as condições sociais de acesso à educação, os meios de produção e de oferta nos subcampos da cultura e as predisposições individuais, social e culturalmente construídas, que, em algum momento da trajetória de uma vida, permitem o desenvolvimento de uma certa prática ou gosto cultural (a operacionalização do habitus diante do horizonte de possíveis, de Bourdieu). Essa compreensão do fenômeno aponta direções para a definição de estudos de públicos - como a investigação sobre visitantes ou não visitantes de museus -, desatrelados dos objetivos perseguidos pelas exposições ou demais serviços oferecidos (Asensio, Pol, s.d). Sem impor marcos normativos ou categorias a priori sobre natureza ou perfil do público, esses estudos reconhecem que o não público de hoje poderá ser o público de amanhã, do mesmo modo que o sentido de uma manifestação cultural é passível de transformação ao longo do tempo e junto a cada segmento social.

\section{O Museu Nacional do Rio de Janeiro e seus públicos}

No ato de criação de um museu no Reino do Brasil em 6 de junho de 1818, dom João VI explicita os objetivos da instituição: propagar o conhecimento e incentivar o estudo das ciências naturais. Os objetivos de identificar e classificar os recursos naturais e a produção cultural brasileira e contribuir para o desenvolvimento das ciências, das artes e da indústria deixam claro que, num primeiro momento, o público-alvo da instituição contituía-se de pesquisadores, viajantes e estudiosos. $\mathrm{O}$ ato também aponta a necessidade de reunir acervos dispersos, como máquinas, instrumentos e gabinetes científicos, entre outros.

O museu originou-se de coleções heteróclitas, nas quais se destacava o conjunto mineralógico classificado por Abraham Gottlob Werner no final do século XVIII, trazido para a Real Academia Militar do Rio de Janeiro em 1810, visando ao ensino da mineralogia. O costume de coletar, tratar e encaminhar para Lisboa exemplares da fauna, da flora e das variadas riquezas do solo da Colônia intensificou-se a partir da segunda metade do Setecentos. Em 1783, o vice-rei dom Luís de Vasconcelos e Sousa projetara a construção de um museu para depósito de objetos zoológicos, no Rio de Janeiro. Antes da inauguração do edifício, os exemplares eram acomodados e tratados em uma pequena construção, a Casa de História Natural, conhecida como Casa dos Pássaros, que funcionava como entreposto das peças - exemplares da fauna brasileira, principal mente aves - que seguiriam para Lisboa.

A crise do sistema colonial sustentou a formação do Museu Real, que encontrou no período de consolidação das ciências modernas, no Império português, as condições 
necessárias para seu desenvolvimento. A competição econômica com as Antilhas acendeu o interesse do governo português pela história natural, em particular pela botânica relacionada à agricultura, à medicina e à química (Lopes, 1997).

Além da finalidade explícita do desenvolvimento das ciências naturais orientado para o fortalecimento econômico da metrópole, se pode observar uma função implícita, a construção, valorização e visibilidade de um patrimônio tornado público e posto a serviço da formação intelectual das elites locais, que contribuiriam para sustentar a implantação da corte no Brasil. O modelo de museu posto em prática na nova sede do Reino foi o europeu, universal e metropolitano, que almejava reunir espécimes de todo o Globo, registrando e expondo a história da natureza e do homem. A afirmação do valor universal da ciência estava em pauta no Rio de Janeiro, cidade que preten dia figurar entre as grandes metrópoles, onde os museus eram um dos atores da dinâmica cultural (Köptcke, 2005).

No decorrer do século XX, outras instituições surgem e desenvolvem-se em solo brasileiro, algumas de forma duradoura. A criação de museus no final do século XIX foi comum em vários países, com ênfase naqueles do continente europeu e dos Estados Unidos. Na América Latina, países aspirantes à independência política afirmavam, por meio dessas instituições, seu grau de civilização: "o grau de civilização que cada nação, cidade ou província tenha atingido é melhor aferido pelo caráter de seus museus públicos e pela liberdade com que eles são mantidos" (Goode, 1895, p.141, citado em Lopes, 1997, p.223). No campo das ciências da natureza foi inaugurado no Pará, em 1871, o Museu Paraense e no Paraná, cinco anos depois, o Museu Paranaense. Em 1895, São Paulo inaugurou o Museu Paulista (atual Museu do Ipiranga). No bojo da preparação das apresentações das províncias nas exposições nacionais e internacionais ${ }^{5}$, e abrindo espaço para estudos e ensino superior, esses museus e o Museu Real participaram da construção do campo científico e da nacionalidade no Brasil.

As visitas ao Museu Real, entre 1818 e 1821, eram privilégio de 'curiosos', estudiosos e autoridades. A primeira exposição pública foi ali realizada no decorrer de 1821. Note-se que a totalidade do acervo não estava aberta à visitação. Apenas quatro salas podiam ser percorridas (cf. Silva Maia, em UFRJ, 2002, p.197), porém através de solicitação por escrito era possível visitar outros espaços. Esse público sel eto incluía professores (lentes) responsáveis por disciplinas científicas de instituições de ensino superior, membros de sociedades científicas, além de naturalistas estrangeiros e diplomatas em visita ao Brasil.

O acesso 'em massa' ao Museu Nacional do Rio de Janeiro', um fluxo de cerca de mil visitantes no período de três meses, foi registrado ainda durante o Império, em 1882, por ocasião da Exposição Antropológica Brasileira (UFRJ, 2002, p.207), considerada por Lacerda (1905, p.57) uma "festa científica e popular, pela primeira vez levada a efeito no Brasil, marcando uma época na história do Museu". Pode-se discutir a ideia de 'acesso em massa' no século XIX, diante da percepção contemporânea. Ademais, embora os museus, em geral, pretendessem, já naquele século, atrair 'multidões', deve-se relativizar a sua dimensão, assim como ressaltar que elas ocorriam em períodos excepcionais, quando uma série de medidas que visavam possibilitar um acolhimento extraordinário era tomada, a exemplo da presença obrigatória da Guarda Real nas salas franqueadas. O acesso em massa aos museus fica igualmente manifesto nos relatórios de gestão dos diretores do Museu Paulista, 
consecutivamente Hermann von Ihering (entre 1894 e 1916) eAfonso d'Escragnolle Taunay (entre 1917 e 1945). No Museu, von Ihering registrou fluxo de 40 mil visitantes por ano, durante o período em que foi diretor, e Taunay, 50 mil visitas em 1917 (Oliveira, 2002-2003).

O Muséum National d'Histoire Naturelle de Paris, que serviu de inspiração ao Museu Nacional do Rio de Janeiro em vários aspectos, afirmava, ao final do século XVIII, sua missão e seu compromisso com o conhecimento científico, e suas galerias, organizadas de acordo com as novas regras de classificação da natureza, forneciam material para novos estudos. Tendo por principal vocação a pesquisa, a maioria de seu público era composta por estudiosos. Lamarck, em 1790, prescrevia que a abertura ao público se fizesse no período da manhã, momento mais apropriado ao trabalho científico, ao contrário das tardes, quando os passantes, em busca de distração, procuravam nas sal as de exposição um remédio contra o tédio (Lamarck, 1790, citado em Van Praet, Démaret, Drouin, 2000).

No caso do Palácio Real do Louvre, seis anos após sua abertura como museu, o público era frequentemente bastante numeroso, quase beirando a multidão (Rapport..., 25 sept. 1799, em Gallard, 1993, p.187). Todavia a afluência ao museu não era diária, pois até 1855 era franqueado ao público geral apenas aos domingos, estando os demais dias reservados a artistas e estrangeiros. Após a Exposição Universal de Paris, em 1855, um novo regulamento abriu o museu a todos os visitantes durante a semana, exceto às segundas-feiras, dia de limpeza. Por outro lado, o acesso generalizado era relatado como fruto da mediação ou de intermediários culturais. $\mathrm{O}$ 'boca a boca' funcionava entre os trabalhadores em busca de um momento de diversão e da possibilidade de compartilhar, como cidadãos republicanos, um espaço simbólico, público e urbano, manifestando atitude designada por al guns autores como sendo de 'boa vontade cultural'. O Museu do Louvre, em 1862, recebia, por mês, entre 20 mil e 30 mil visitas.

No entanto, o Museu era espaço também frequentado pelas figuras do poder, uma vez que, tanto no Antigo Regime como na nova República, a visita a ele integrava a agenda das recepções oficiais de convidados de prestígio, e simbolizava o uso ideológico da instituição, cuja finalidade política foi reconhecida desde sua criação (Poulot, 1985).

O Louvre, museu oficial da nova República francesa, demorou 62 anos para franquear irrestritamente o acesso a pelo menos uma parte de suas coleções, ao passo que o Museu Nacional levou 93 anos para fazer o mesmo. O intervalo entre a instituição de um museu como espaço público, simbolicamente a serviço do coletivo de cidadãos de uma nação, e a possibilidade de efetivo acesso a ele por parte de segmentos sociais variados espel ha, na gestão das prioridades, a oposição entre o investimento na preservação das coleções para ensino e estudo e a organização do museu com propósitos de divulgação do conhecimento e instrução pública. A mudança na forma como o museu enten de sua missão e estrutura o acolhimento dos públicos ocorre de forma processual, fruto de relação negociada entre seus profissionais, sob forte influência da orientação do diretor responsável.

O decreto de 15 de janeiro de 1911, que criou o novo regulamento do Museu Nacional, estabeleceu sua abertura todos os dias, exceto às segundas-feiras. A instituição recebeu, após a mudança para a Quinta da Boa Vista, em 1892, cerca de 40 mil visitas por ano. Em 1893, foi inaugurado um Livro de Visitantes, que registrava o número de visitas por dia e mês. Durante os anos anteriores, as condições de acesso variaram. Em 1848 a exposição 
pública foi transferida das quintas-feiras para os domingos - exceto os domingos de Páscoa, da Ressurreição e durante o Advento -, fechando às quintas-feiras. Após a mudança do Museu, as visitas públicas passaram a acontecer às sextas-feiras e aos sábados e domingos. A análise dos dados do Livro de Visitantes durante a virada do século XIX para o XX indica aumento do número de visitas de $11 \%$ entre 1900 e 1905 e de $28 \%$ entre 1905 e 1907 (23.318, 26.194 e 36.573 visitantes/ano, respectivamente).

Os dados compilados pela Direção Geral de Estatística, aos quais já nos referimos, organizaram o levantamento do fluxo de visitas aos museus brasileiros nos primeiros anos do século XX, permitindo tecer análises comparativas. ${ }^{7}$ Observando a Tabela 1, referente à frequência dos museus Goeldi, Paulista e Nacional entre 1894 e 1907, percebe-se que o aumento das visitas não constituiu curva ascendente a cada ano em nenhuma das instituições aferidas.

\begin{tabular}{cccc}
\multicolumn{4}{c}{ Tabela 1: Frequência dos Museus Goeldi, Paulista e Nacional (1894-1907) } \\
\hline Ano & Museu Goeldi & Museu Paulista & Museu Nacional \\
\hline 1894 & - & - & 11.308 \\
1895 & - & - & 14.793 \\
1896 & - & 40.000 & 15.641 \\
1897 & 75.671 & 32.315 & 16.994 \\
1898 & 85.172 & 32.965 & - \\
1899 & 79.167 & 32.063 & - \\
1900 & 91.434 & 28.484 & 23.318 \\
1901 & 88.008 & 26.672 & 17.751 \\
1902 & 93.018 & 21.536 & 18.804 \\
1903 & 80.189 & 34.813 & 12.514 \\
1904 & 92.637 & 37.781 & 25.584 \\
1905 & 94.225 & 48.758 & 26.194 \\
1906 & 116.159 & 44.619 & 33.458 \\
1907 & 124.670 & 40.660 & 36.573 \\
\hline
\end{tabular}

Fonte: Brasil, 1927.

O aumento significativo da visitação pode ser atribuído, quase sempre, a fatos extraordinários como festejos nacionais e real ização de grandes exposições. Já a diminuiç̧ão de visitas é associada às condições do transporte urbano, que dificultaria o acesso aos museus (Oliveira, 2002-2003), ou a reformas nas instituições, que diminuíam as áreas abertas à visitação. Ao classificar os museus pela média de visitação anual durante os períodos de abertura ao público em geral (1900-1907), o Museu Goeldi aparece como o mais visitado, com média anual de 97.542 visitantes, seguido pelo Museu Paulista, com 35.415, e pelo Museu Nacional, com 24.274. Para analisar as diferenças na proporção de visitas entre os museus, é necessário levar em conta, entre outros fatores, as práticas culturais e de lazer de cada cidade, o tamanho e perfil sociocultural da população e a oferta cultural existente.

Os relatos sobre o número de visitantes nos primórdios do Museu Nacional, a partir do início do século XX, sugerem a preocupação de ampliar o alcance público da instituição. Mas o que se pode inferir de tais relatos? Qual o critério para se definir o que poderia então ser chamado de multidão? Quem eram essas pessoas e como vinham ao museu? Diversos 
Luciana Sepúlveda Köptcke, Marcele Regina Nogueira Pereira

tipos de visitantes e modalidades de uso aparecem em filigrana nos documentos que registraram a vida cotidiana dessa instituição.

\section{A historiografia dos museus e os estudos de público}

Até meados do século XX, a história dos museus ficou muitas vezes restrita aos relatos de seus diretores. George Brown Goode, em 1888, apresenta o primeiro artigo que trata formalmente da história dos museus norte-americanos, no 3 e Encontro Anual da Associação Histórica Americana (Washington). Nesse texto, discute o lema do American Museum of Natural History, "Para o povo, para a educação, para a ciência" (For the people, for education, for science), e apresenta uma historiografia que não recorre a fontes primárias ou mesmo a secun dárias. No rastro de Goode, muitos foram os diretores e estudiosos de museus a escrever sobre suas instituições, como, por exemplo, Ladislau Netto, diretor de Museu Nacional do Rio de Janeiro (Lopes, 1997).

O museólogo e historiador mexicano Morales Moreno afirma que a historiografia dos museus não era relevante no âmbito da pesquisa acadêmica da história institucional. Foi a partir da década de 1980 que os museus passaram a ser valorizados como objeto de estudo em disciplinas diversas, valorização acompanhada pela consolidação da museologia como área de reflexão teórica e de ação prática (Morales-Moreno, 1994, p.13-14, em Lopes, Muriello, 2005).

Poulot (2000) distingue quatro perspectivas históricas ou quatro historiografias sobre os museus: uma história da fundação dos museus, de suas origens a sua disseminação; uma história das permanências, dos fragmentos narrativos passados e presentes que, superpostos, coabitam as salas de uma mesma instituição, desvelando os processos de construção de legitimidade cultural; uma terceira perspectiva, que remete à história dos objetos colecionados, das vicissitudes das coleções, e pode constituir uma história paralela à do museu; e finalmente uma história da representação museográfica, revelan do como os museus eram percebidos e apropriados pelos sujeitos que neles trabalhavam, pesquisavam, ensinavam ou apenas os visitavam - essa 'meta-história' das instituições museais dialoga com os estudos da história europeia sobre as formas de fruição das obras de arte e dos objetos do patrimônio histórico e científico. O autor sinaliza que faltam estudos sobre as escolhas dos curadores e uma sociologia desses atores e aponta a fragilidade da história dos museus, à semelhança do que ocorre com a história da cultura material e mesmo com a história das ciências.

Lopes e Murriello (2005, p.15), baseando-se em Oroz (1990), Schnitter (1996) e Levinton e Aldrich (2000) para desenhar um panorama da historiografia dos museus, indicam que seria de interesse a definição de marcos e critérios de periodização, e citam a importância de considerar a especificidade dos diferentes momentos da instituição. Comentam também os 'sistemas museais', formulação que Pearce (1989) empregou para descrever os processos de elaboração, exposição, comunicação e interpretação da cultura (material) que ocorrem em museus. As autoras destacam igualmente a importância de tomar "as próprias coleções e as relações sociais em torno del as como objeto de uma historiografia dos museus" el egendo como foco de seu trabalho a "ciência e a educação em museus, nas últimas décadas do século XIX e nas primeiras do XX" (Lopes, Murriello, 2005, p.16). Sugerem ainda um 
aprofundamento teórico-metodológico sobre a história dos museus, no que se refere aos aspectos comunicativos, expositivos, educacionais e científicos.

A presença do visitante nos discursos sobre o museu, embora constante, suscita níveis variados de atenção e interesse. De acordo com o foco, o visitante ou usuário pode ter uma importância secundária ou ser o ponto central da pesquisa. No campo histórico, os públicos e as práticas de visita foram considerados, na Europa dos anos 1960 e 1970, objeto de uma história dos costumes, despertando menos interesse do que, por exemplo, as exposições universais, consideradas experiências de cultura de massa e, por isso, mais relevantes para esses estudos.

No Brasil, os museus ocuparam a cena em pelo menos três frentes de reflexão histórica e social: aquela voltada para a história das ciências no país (Lopes, 1997; Schwarcz, 1993, 1989); os estudos sobre a construção da nacionalidade, memória e história (Santos, 1992, 2002; Meneses, 1985, 1993, 1995; Brefe, 1999; Alencar, 2001); e ainda estudos sobre a construção dos espaços de educação e da cultura científica (Valente, 1995, 2009; Studart, Almeida, Valente, 2003). ${ }^{8}$

Ao considerar o museu um local de práticas e narrativas simbólicas, os estudos de público constroem-no como espaço de recepção (cultural) dos discursos museais e constroem sua história como sendo a dos olhares dos visitantes sobre os museus. ${ }^{9}$ No entanto, os públicos ainda não foram objeto de estudos históricos específicos no Brasil, aparecendo apenas 'transversalmente' em estudos sobre os museus, nos aspectos mencionados e, em particular, quando se analisam as agendas políticas das instituições.

Os públicos constituem, pois, importante categoria de análise para adensar a reflexão sobre o papel social dos museus. Sua eleição como objeto de estudo convida o pesquisador a direcionar um novo ol har sobre as fontes já conhecidas e empregadas em outras leituras. O Guia de fontes primárias foi elaborado para oferecer aos pesquisadores um instrumento que facilite o acesso aos acervos históricos com fontes documentais pertinentes, e para aprofundar a análise sobre a relação dos públicos com o museu no século XIX no Rio de Janeiro, em uma instituição que guarda materiais relevantes sobre essa temática: o Museu Nacional do Rio de Janeiro.

\section{Apresentação do Guia: critérios de busca, base consultada, características dos registros, observações sobre sua estrutura, limites e contribuições}

As instituições museológicas guardam grande quantidade de documentos oficiais, cartas, relatórios e regimentos, com dados e informações sobre os visitantes e os variados usos possíveis da instituição em certo período. Esses documentos oferecem um vasto campo de investigação e interpretação, contribuindo para a compreensão do significado dos museus para o público e vice-versa. O Guia de fontes primárias: Museu Nacional - seu público no sécul $\mathrm{XIX}$ e no início do XX ${ }^{10}$ visa orientar efacilitar a busca de informações que contribuam para o conhecimento dos modos de apropriação social do Museu, no período em questão.

A ideia de realizar um guia de fontes surgiu no âmbito das pesquisas do então incipiente Observatório de Museus e Centros Culturais (OMCC) ${ }^{11}$, em 2002. Durante uma visita à biblioteca do Instituto Brasileiro de Geografia e Estatística, as autoras depararam com 
instigantes dados sobre museus, no Anuário estatístico do Brasil. Sua primeira edição cobria o período de 1908 a 1912, e os dados sobre últimos anos do século XIX foram publicados em 1927 (Brasil, 1927). No primeiro Anuário, apresentam-se alguns museus, a natureza e a extensão de suas coleções, assim como o número de visitantes por ano. Tal descoberta desencadeou questionamentos sobre como esses dados eram produzidos nas diferentes instituições e qual seria sua finalidade. A fim de buscar respostas a essas indagações, iniciamos uma pesquisa que visava encontrar as informações originadas nos próprios museus e sistematizá-las. Entre os museus citados no Anuário (Paulista, Goeldi, Nacional, entre outros), o primeiro a ser objeto de estudo foi o Museu Nacional, em particular seu acervo institucional. O guia de fontes deveria abarcar diversos acervos de diferentes instituições, porém, devido a questões de ordem financeira e logística, restringiu-se ao Museu Nacional, abraçando os acervos que descreveremos a seguir, bem como os critérios empregados para a sua organização.

Em um guia de fontes, cabe apresentar os critérios utilizados para localização, reunião e organização dessas fontes. $\mathrm{O}$ assunto de abrangência deve estar exposto com clareza e precisão. Além de obedecer rigidamente aos critérios de agrupamento e às definições do tema proposto, também deve ser apontado o suporte das informações, ou seja, sob que forma ela foi consolidada: imagem (fotografia ou filme), manuscrito ou impresso (documentos textuais) ou ainda fita cassete, no caso dos depoimentos de história oral.

Para os propósitos de elaboração do Guia de fontes, consideramos público do Museu todos aqueles que de al guma forma o utilizaram. Assim, encontram-se nessa categoria não só o público visitante das exposições, mas também pesquisadores e estudiosos das coleções científicas, professores que lecionaram no Museu, estudantes que solicitaram ajuda e orientação, cientistas que contribuíram com doações e realizaram intercâmbios científicos etc. O conceito de público empregado para a elaboração deste guia foi, portanto, plural, visando mapear os diferentes usos da instituição.

Inicial mente realizou-se o levantamento dos locais de guarda de documentos pertinentes ao escopo do Guia, na cidade do Rio de Janeiro: Arquivo Nacional; Biblioteca Nacional; biblioteca do Instituto Histórico e Geográfico Brasileiro; biblioteca do IBGE; biblioteca do Instituto do Patrimônio Histórico e Artístico Nacional; além da biblioteca e dos arquivos do Museu Nacional. Diante do volume de documentos identificados e da falta de tempo, no âmbito do projeto, para coletar todas as informações, optou-se por apresentar, no Guia, apenas o acervo do Museu Nacional. A escolha levou em consideração o fato de ele ter sido uma das primeiras instituições do gênero no país, em funcionamento desde 1818.

O Museu Nacional possui vasto acervo documental, que inclui uma biblioteca, o que se traduz em grande volume de informações, que permitiria a seleção no tempo estipulado para a pesquisa. Os documentos do acervo remontam ao período de criação da instituição, no século XIX, e informações continuam a ser produzidas até os dias de hoje. Seguindo a periodização da pesquisa e a organização do arquivo, o Guia se detém apenas nas fontes que remontam ao século XIX e aos anos iniciais do século XX. Apresenta, ainda, uma listagem de documentos que não fazem parte do acervo do Museu Nacional; essas informações constituem sua quarta parte ("Fontes complementares") e foram incluídas 
por sua relação direta com o Museu Nacional, constituindo fontes complementares de pesquisa; tais fontes não serão comentadas neste texto.

\section{A Seção de Memória e Arquivo do Museu Nacional e a natureza do acervo selecionado}

O acervo da Seção de Memória e Arquivo do Museu Nacional (Semear) permite investigar aspectos do funcionamento cotidiano do Museu Nacional, sua relação com instituições congêneres, nacionais e estrangeiras, e subsidia a compreensão das ações e realizações do Museu no contexto político, econômico e social brasileiro. São documentos que registram os primórdios do trabalho científico no Brasil e as alterações ocorridas no cenário internacional das ciências. Além disso, a seção custodia diversos arquivos pessoais de cientistas e professores.

O objetivo da seção é promover a recuperação e disseminação das informações contidas na documentação arquivística e garantir sua integridade física, subsidiando o desenvolvimento de pesquisas sobre a história do Museu Nacional e do Palácio Imperial e, principalmente, sobre a institucionalização das ciências no Brasil.

A origem da seção remonta à implementação, na década de 1990, do Projeto Memória do Museu Nacional, que possibilitou, a partir de 1994, a informatização do catálogo e a higienização, a identificação e o acondicionamento primário dos documentos do século XIX, projetos financiados pela Fundação Vitae e pela Fundação de Amparo à Pesquisa do Estado do Rio de Janeiro (Faperj).

No processamento da sua documentação, o Museu Nacional faz uso de nova metodologia, a Descrição Multinível Integrada (DMI), bem como de sistema informatizado, o Sistema de Informações do Arquivo Nacional (Sian), em decorrência de cooperação técnica entre o Museu e o Arquivo Nacional.

\section{O Sistema de Informações do Arquivo Nacional}

O Sistema, também disponível em plataforma digital do Museu Nacional, possibilitou o acesso a documentos guardados em pastas, identificadas por numeração correspondente a datas. Permite ao pesquisador o acesso aos documentos pel os seus títulos, com informações e resumos descritivos. Com a seleção inicial realizada através desse sistema, apenas os documentos que se adequavam aos critérios da pesquisa foram analisados inteiramente. $A$ seguir, um exemplo de como as informações são apresentadas no Sian e como selecionamos o acervo que continha apenas dados referentes ao século XIX.

Fundo público pesquisado - Título: Museu Nacional - 1810 a 2004.

Código de Referência: BR MN MN.

Produtor: Museu Real, 1818-1824.

Museu Nacional e Imperial, 1824-1825.

Museu Imperial e Nacional, 1825-1842.

Museu Nacional, 1842- 2004.

A seguir, encontra-se o caminho de busca utilizado para a pesquisa ilustrada no exemplo acima. 


\section{Título: Museu Nacional / BR MN MN / Fundo / Público / Datas: 1810 a 2004}

Este fundo é dividido em vários grupos: Administração; Antropologia - Etnologia Arqueologia - Botânica; Congregação; Conselho Administrativo; Conselho Departamental; Diretoria; Entomologia; Escritório Técnico Científico; Estação Biológica; Geologia e Paleontologia; Invertebrados; Laboratório de Química; Laboratório de Química Geral Analítica; Laboratório de Química Vegetal; Portaria; Serviço de Museologia; Zoologia. Esses títulos espel ham as várias divisões nas quais o Museu Nacional esteve organizado, e cada um deles, com sua especificidade, possui vasta documentação referente ao movimento diário. Apresentam fontes datadas do século XX, que, portanto, extrapolam os limites temporais do Guia de fontes.

Apenas os títulos Diretoria e Consel ho Administrativo apresentam documentação referente ao século XIX; assim, a pesquisa de fontes foi exclusivamente realizada com base nos documentos desses títulos:

\section{Título: Conselho Administrativo}

Documentos: Registro das atas e deliberações do Conselho Administrativo do Museu Nacional. Livro n.1.

Código de referência: BR MN MN CD 1 Início: 1/3/1842 Término: 17/7/1854

Registro das atas e deliberações do Conselho Diretor. Livro n.3

Código de referência: BR MN MN CD 2 Início: 22/2/1876 Término: 13/2/1885

Registro das atas e referências do Conselho Diretor. Livro n.4

Código de referência: BR MN MN CD 3 Início: 10/3/1885 Término: 29/4/1893

Registro das atas e referências do Conselho Diretor. Livro n.5

Código de referência: BR MN MN CD 4 Início: 1/6/1893 Término: 17/3/1904

\section{Título: Diretoria}

Código de Referência BR MN MN DR

Subtítulos: Assuntos Gerais; Circulares; Correspondência; Finanças; Informativos; Materiais; Material Científico; Pessoal; Portarias.

Em Diretoria, apenas Correspondência faz referência ao século XIX:

Subtítulo: Correspondência

Em Correspondência encontramos os seguintes subtítulos: Avisos e Ofícios; Cartas; Registro de avisos, ordens, decretos, ofícios e portarias.

- Avisos e Ofícios (AO) Código de Referência: BR MN MN DR CO, AO nível 3.5 subsérie;

- Cartas (CA) Código de referência: BR MN MN DR CO, CA nível 3.5 subsérie;

- Registros de avisos, ordens, decretos, ofícios e portarias

Código de referência: BR MN MN DR CO, RA nível 3.5 subsérie

No subtítulo Cartas encontramos, no subtítulo Vários Documentos, cartas datadas a partir de 1915, a exemplo de:

- Cartas expedidas, referentes à permuta de material científico, serviço de policiamento do museu, excursões científicas etc.;

- Cartas expedidas referentes a estatísticas de visitantes, publicações, permuta de material etc. Data: 1940; 
- Cartas expedidas referentes a cursos. Fotografias etc.

O Guia apresenta listagem de todos os documentos encontrados no fundo público Museu Nacional 1818-2004, título Diretoria, subtítulo Correspondência, que de alguma forma tratam das relações do Museu Nacional com seu diversificado público e seus diferentes usos e apropriações no século XIX. São 130 documentos, cuja relação respeita a seguinte ordem de informações:

- Tipo: referese ao tipo de documento selecionado;

- Data: a data de produção do documento; em alguns casos consta apenas o ano;

- Localização: local onde o documento pode ser encontrado nos arquivos Sian do Museu Nacional;

- Resumo: pequena síntese do documento.

A maioria é composta de ofícios e avisos (105). As cartas são apenas 16 e os regimentos, nove.

\section{Os Livros de Visitantes do Museu Nacional}

O Livro de Visitantes do Museu Nacional apresenta informações ricas e detal hadas sobre os públicos que visitaram o Museu Nacional entre 1893 e 1931 erepresenta, a princípio, um primeiro esforço de controle sistemático dos públicos visitantes, razão por que foi incluído no Guia. Além da natureza peculiar, esse registro chamou a atenção também pela organização das informações e riqueza de detalhes que apresenta. O primeiro Livro de Visitantes data do século XIX, de 1893, e inclui também dados do século XX. Apresentamos no Quadro 1 um resumo com algumas informações contidas nessas fontes documentais.

\section{Quadro 1: Livro de Visitantes do Museu Nacional}

\begin{tabular}{|c|c|}
\hline Data: & 14/07/1893 a março de 1910 \\
\hline Resumo: & $\begin{array}{l}\text { A primeira página do livro apresenta a seguinte frase: "Visitantes do Museu - } 1894 \text { ". } \\
\text { A segunda página apresenta a lista dos visitantes do Museu Nacional no período de } \\
14 \text { de julho de } 1893 \text { até } 1910 \text {. Essa página apresenta também o total de visitantes por } \\
\text { meses e por ano. }\end{array}$ \\
\hline Data: & 1914 a 1931 \\
\hline Observações: & $\begin{array}{l}\text { Não foram encontrados os registros de visitantes referentes aos anos de 1911, 1912, } 1913 . \\
\text { O volume começa com a seguinte menção do diretor: "Servirá o presente livro para } \\
\text { registro do movimento de visitantes ao MN e contém o número de folhas constantes do } \\
\text { termo de encerramento. Museu Nacional do Rio de Janeiro, em outubro de } 1914 . \\
\text { O diretor." }\end{array}$ \\
\hline
\end{tabular}

\section{Limites e contribuições}

Guias de fontes organizam e orientam o acesso à informação. Alguns itens característicos os tornam instrumentos valiosos para os pesquisadores que trabal ham com documentos históricos, entre eles: a identificação detal hada de instituições que guardam documentos sobre a temática de interesse do guia; a identificação e listagem das pastas em que os 
documentos estão agrupados e guardados; a localização de documentos dentro de uma lógica; informações adicionais como estado de conservação, autor/autores, data, detal hes sobre a divisão em séries ou subséries documentais e, nesse caso, a localização das séries complementares, e se existem cópias.

O Guia de fontes primárias: o Museu Nacional - seu público no século XIX e no início do XX apresenta uma relação com 130 documentos com informações diretas ou indiretas sobre a relação do público com o Museu no período. Não pretende esgotar o universo de documentos sobre o tema; com ele se afirma a pertinência de sistematizar informações sobre visitantes e públicos dos museus em acervos históricos, e preten de inspirar a elaboração de levantamentos similares. Foram listadas e selecionadas todas as fontes sobre $\mathrm{o}$ assunto datadas do século XIX e primeiros anos do XX, que integram o acervo histórico sob a guarda da Seção de Memória e Arquivo do Museu Nacional.

Documentos de outros fundos, que não foram alvo de análise aqui, podem apresentar outras referências sobre o público do museu. Futuras pesquisas, mais abrangentes e detalhadas, que reúnam todas as fontes sobre o público de museus nos séculos XIX e XX, e façam uma análise dessa produção segundo sua natureza, finalidade e âmbito de circulação, podem colaborar para a melhor compreensão das modalidades de apropriação social das instituições museais.

\section{NOTAS}

1 Edward Robinson, professor de psicologia da Universidade de Yale, em palestra sobre o tema da educação pública em saúde, no 61ํ Encontro Anual da Associação Americana de Saúde Pública, em 1932, defendeu a necessidade de abordar a questão da educação por métodos experimentais: “Minha proposta é que enfrentemos o problema da inteligência humana com a mesma humildade do homem de ciências diante de outras áreas complexas dos fatos naturais" (Robinson, 1933, p.123; tradução livre).

2 Nesta e nas demais citações de textos em outros idiomas, a tradução é livre.

${ }^{3}$ Sem pretender a exaustão da literatura sobre o tema, nas áreas de educação, comunicação, antropologia/ etnografia, história, psicologia, marketing, museologia, e sociologia podemos mencionar: Chagas, 1987; Silva, 1989, Beltrão et al., 1990; Fal cão, 1990; Freire, 1990, 1993; Cazelli, 1992,; Carvalho, 1998; Carvalho, 1994; Barbosa, 1994; Valente, 1995; Studart, 1997; Vieira, 1997; Almeida, 1995, 1998; e Cury, 1999.

4 A categoria 'não público' corresponde aos indivíduos que, segundo pesquisas de práticas culturais, afirmam não praticar determinada atividade cultural. Conhecer o perfil e a motivação que levam o não público a desprezar determinada prática é relevante para o campo dos estudos da cultura.

${ }^{5}$ Referimos-nos, particularmente, à Exposição Internacional de Viena, em 1873, à Exposição Nacional de 1875 e à da Filadélfia, no mesmo ano, e à Exposição Antropológica Brasileira, em 1882 (Lopes, 1997).

6 Doravante denominado Museu Nacional.

${ }^{7}$ No entanto, deve-se observar com certa precaução a análise comparativa entre os números registrados no Anuário, pois as formas de construção de tais informações podiam diferir em cada museu. Além disso, os dirigentes ten diam a apresentar as informações de forma a valorizar o sucesso de sua instituição, posto que a frequência do público era já considerada um critério de validação social (Lopes, 1997; Oliveira, 2002-2003).

${ }^{8} \mathrm{Não}$ se pretende, aqui, abordar exaustivamente a produção nacional com foco na história dos museus, ou mesmo como estes aparecem em outras historiografias (construção da República no Brasil, memória social, história da arte ou das ciências, entre outras). Nossa intenção é lembrar as áreas de conhecimento em que os museus foram amiúde objeto de análises e, nelas, a leitura sobre a natureza dos usos sociais dos museus.

${ }^{9}$ Conforme anotações de aula do curso Diplôme d’Études Approfondies, em museologia, oferecido no período acadêmico 1994/1995 pelo Conservatoire des Arts et M étiers, Muséum National d'Histoire Naturelle de Paris, Université Jean Monnet, Saint Étienne. 
${ }^{10} \mathrm{O}$ Guia defontes primárias encontra-se disponível no sítio do Observatório de M useus e Centros Culturais (www.fiocruz.br/omcc), na seção Estante Virtual/Publicações do OMCC. Foi realizado no âmbito do projeto Estudos de Público, Contar Para Conhecer?: A Contribuição de Dados Quantitativos Para a Avaliação do Impacto dos Museus na Democratização do Acesso à Cultura na Sociedade Brasileira, com apoio da bolsa de Aperfeiçoamento Técnico da Faperj (acordo Faperj/Fiocruz 2003-2007). Agradecemos a contribuição de M aria Rachel Fróes, pesquisadora da Casa de Oswaldo Cruz, cuja generosa interlocução no processo de elaboração do Guia consistiu em apoio imprescindível à sua realização.

${ }^{11}$ O OMCC é projeto de pesquisa, sistematização e compartilhamento de informações sobre museus e sua relação com a sociedade. É fruto de parceria entre a Fundação Oswaldo Cruz e o Instituto Brasileiro de Museus, com apoio do Museu de Astronomia e Ciências Afins e da Escola Nacional de Ciências Estatísticas. Para mais informações, ver www.fiocruz.br/omcc.

\section{REFERÊNCIAS}

ALMEIDA, Adriana Mortara.

Evaluation of the Butantan Institute Museum: limits of the quantitative approach. In:

Dufresne Tassé, C. (Ed.). Évaluation et éducation muséales: nouvelles tendances. Québec: CECA/ ICOM. p.121-136. 1998.

ALMEIDA, Adriana Mortara.

A relação do público com o Museu do Instituto Butantan: análise da exposição Na Natureza não Existem Vilões. Dissertação (M estrado) Escola de Comunicações e Artes, Universidade de São Paulo, São Paulo. 1995.

ALVES, Ana Maria de Alencar.

O Ipiranga apropriado: ciência, política e poder o Museu Paulista, 1893-1922. São Paulo: Humanitas. 2001.

ASENSIO, Mikel; POL, Elena.

Cuando la mente va al museo: um enfoque cognitivo-receptivo de los estúdios de público. Madrid: Universidad Autónoma de Madrid. Mimeo. s.d.

BARBOSA, Andrea C.M. Marques. MASP: um museu e seu público. Dissertação (Mestrado) - Museu Nacional, Universidade Federal do Rio de Janeiro, Rio de Janeiro. 1994.

BECKER, Howard.

Les mondes de I'art. Paris: Flammarion. 1988.

BECKER, Howard.

Art as a collective action. American Sociological Review, Washington, v.39, n.6, p.767-776. 1974.

BELTRÃO, Kaisô I. et al.

Perfil de visitantes de museus: relatório técnico. Rio de Janeiro: Escola Nacional de Ciências Estatísticas/Instituto Brasileiro de Geografia e Estatística. 1990.

BOURDIEU, Pierre; DARBEL, Alain.

O amor pela arte: os museus de arte na Europa e seu público. São Paulo: EdUSP. 2003.

BRASIL.

Ministério da Agricultura e Comércio. Diretoria
Geral de Estatística. Annuário estatístico do Brasil, 1908-1916, v.2, ano 1. Rio de Janeiro: Typographia de Estatística. 1927.

BREFE, Ana Cláudia Fonseca.

Um lugar de memória para a nação: o Museu Paulista reinventado por Affonso d'Escragnolle Taunay (1917-1945). Tese (Doutorado) Instituto de Filosofia e Ciências Humanas, Universidade Estadual de Campinas, Campinas. 1999.

CARVALHO, Márcia $M$. Perfil dos visitantes do Museu Nacional de Belas Artes. Rio de Janeiro: Escola Nacional de Ciências Estatísticas. 1994.

CARVALHO, Rosane Maria Rocha. Exposição em museus e público: o processo de comunicação e transferência da informação. Dissertação (Mestrado) - Escola de Comunicação, Universidade Federal do Rio de Janeiro, Rio de Janeiro. 1998.

\section{CAZELLI, Sibele.}

Alfabetização científica e museus interativos de ciências. Dissertação (M estrado) -

Departamento de Educação, Pontifícia Universidade Católica do Rio de Janeiro, Rio de Janeiro. 1992.

CAZELLI, Sibele; MARANDINO, Martha; STUDART, Denise.

Educação e comunicação em museus de ciência: aspectos históricos, pesquisa e prática. In: Gouvêa, Guaracira; Marandino, M.; Leal, Maria Cristina (Org.). Educação e museus: a construção do caráter social dos museus de ciência. Rio de Janeiro: Access. p.83-106. 2003.

CHAGAS, Mário.

Museu: coisa velha, coisa antiga. Rio de Janeiro: Unirio. 1987.

CURY, Marília Xavier.

Exposição: análise metodológica do processo de concepção, montagem e avaliação. Dissertação 
(Mestrado) - Escola de Comunicação e Artes, Universidade de São Paulo, São Paulo. 1999.

DAVEY, Gareth.

What is museum fatigue?. Visitors studies today, v.8, n.3, p.17-21. 2005.

DONNAT, Olivier; COGNEAU, Denis. Les pratiques culturelles des français, 1973-1989. Paris: La Découverte. (La Documentation Française). 1990.

FALCÃO, Douglas

Padrões de interação e aprendizagem em museus de ciência. Dissertação (Mestrado em Educação, Gestão e Difusão de biociências) - Instituto de Ciências Biomédicas, Universidade Federal do Rio de Janeiro, Rio de Janeiro. 1990.

FALK, John; DIERKING, Lynn.

The museum experience. Washington: Whal esback Books. 1992.

FREIRE, Maria Cristina.

Museu. Público. Arte contemporânea. Um triângulo nem sempre amoroso. Arte Unesp, São Paulo, v.9, p.131-146. 1993.

FREIRE, Maria Cristina.

Olhar passageiro: percepção e arte contemporânea na Bienal de São Paulo. Dissertação (Mestrado) - Instituto de Psicologia, Universidade de São Paulo, São Paulo. 1990.

GALARD, Jean.

Visiteurs du Louvre: un florilège. Paris: Reunion des Musées Nationaux. 1993.

HIGGINS, Henry Hugh.

Museums of natural history, part 1: Museum visitors. Transactions of the Literary and Philosophical Society of Liverpool, Liverpool, p.185- 88. 1884.

HOLANDA, Aurélio Buarque de Novo dicionário Aurélio. Rio de Janeiro: Nova Fronteira. 1975.

KÖPTCKE, Luciana Sepúlveda.

Bárbaros, escravos e civilizados: o público dos museus no Brasil. Revista do Patrimônio Histórico e Nacional, Rio de Janeiro, n.31, p.184-205. 2005.

KÖPTCKE, Luciana Sepúlveda.

Observar a experiência museal: uma prática dialógica? In: Fundação Oswaldo Cruz. Casa de Oswaldo Cruz. Museu da Vida. Avaliação e estudos de público de museus e centros de ciência. p.5-21. (Cadernos do Museu da Vida, 2). 2003. KÖPTCKE, Luciana Sepúlveda; PEREIRA, Marcelle.

O estudo da produção de dados estatísticos oficiais sobre hábitos culturais e práticas de
Iazer no Brasil. Pôster apresentado na 3. Bienal de Pesquisa da Fiocruz, nov. 2002,

Rio de Janeiro. 2002.

LACERDA, João Batista de.

Faustos do Museu Nacional do Rio de Janeiro: recordações históricas e científicas, fundadas em documentos autênticos e informações verídicas. Rio de Janeiro: Imprensa Nacional. 1905.

\section{LAHIRE, Bernard.}

La culture des individus: dissonances culturelles et distinction de soi. Paris: La Découverte. 2004.

LEVINTON, Alan E.; ALDRICH, M.L. India: a case study of natural history in colonial setting. In: Ghiselin, Michael T.; Levinton, Alan E. (Ed.). Cultures and institutions of natural history. São Francisco: California Academy of Sciences. p.51-80. 2000.

\section{LOPES, Maria Margaret.}

Museus e educação na América Latina: o modelo parisiense e os vínculos com as universidades. In: Gouvêa, G.; Marandino, M.; Leal, C. (Ed.). Educação e museu: a construção social do caráter educativo dos museus de ciência. Rio de Janeiro: Access. p.63-82. 2003.

LOPES, Maria Margaret.

O Brasil descobre a pesquisa científica: os museus e as ciências naturais no século XIX. São Paulo: Hucitec. 1997.

LOPES, Maria Margaret; MURRIELLO, Sandra Elena.

Ciências e educação em museus no final do século XIX. História, Ciências, Saúde -

Manguinhos, Rio de Janeiro, v.12, supl., p.13-30. 2005.

MACMANUS, Paulette M.

Frames of reference: changes in evaluative attitudes to visitors. Journal of Museum Education, Washington, v.21, n.3, p.3-5. 1997.

MELTON, Arthur Weever.

Studies of installation at the Pennsylvania Museum of Art. Museum News, v.10, n.14, p.5-8. 1933.

MENESES, UIpiano Toledo Bezerra. Do teatro da memória ao laboratório da história: a exposição museológica e o conhecimento histórico. Anais do Museu Paulista, São Paulo, n.2, p.9-84; n.3, p.83-121. 1995.

MENESES, Ulpiano Toledo Bezerra de. A problemática da identidade cultural nos museus: de objetivo (de ação) a objeto (de conhecimento). Anais do Museu Paulista, São Paulo, n.1, p.207-222. 1993. 
MENESES, Ulpiano Toledo Bezerra de. O museu na cidade/a cidade no museu: para uma abordagem histórica dos museus de cidade. Revista Brasileira de História, São Paulo, v.5, n.8-9, p.197-206. 1985.

MORALES-MORENO, Luis Gerardo.

Origines de la museologia mexicana: fuentes para el estudio histórico del Museo Nacional, 1780-1940. México: Universidade Iberomaericana. 1994.

MOUTCHOURIS, Antigone.

Sociologie du public dans le champ culturel et artistique. Paris: L'Harmattan. 2003.

OLIVEIRA, Cecília Helena Salles de.

Museu Paulista: espaço de evocação do passado e reflexão sobre a história. Anais do Museu Paulista, São Paulo, v.10-11, n.11, p.105-126. 2002-2003.

OROZ, Joel J.

Curators and culture: the museum mouvement in America, 1740-1870. Tuscaloosa: The University of Alabama Press. 1990.

PEARCE, Susan (Org.).

Museums studies in material culture. London: Leicester University Press. 1989.

POMIAN, Krzysztof.

Collectionneurs, amateurs et curieux: Paris-Venise, XVI-XVII siècle. Paris: Gallimard. 1987.

POULOT, Dominique.

La naissance d'une tradition européenne. In: Publics et Projets Culturels: un enjeu des musées en Europe. Paris: L'Harmattan, p.24-37. 2000.

POULOT, Dominique.

$L$ 'invention de la bonne volonté culturelle: I 'image du musée au XIX siècle. Le M ouvement Social, Paris, n.131, p.35-64. 1985.

\section{RAPPORT...}

Rapport du 3ème Vendimaire. An. VIII. Procès verbaux de l'Administration du Museum National des Arts, séries 1 BBA, séance n.279, p.205 (Archives du Louvre). 25 sept. 1899.

ROBINSON, Edward.

The psychology of public education. American Journal of Public Health and the Nation's Health, Washington, v.23, n.2, p.123-128. 1933.

ROBINSON, Edward.

The behavior of the museum visitor. Washington: American Association of Museums. (Monograph, New Series, n.5). 1928.

SANTOS, Miriam Sepúlveda dos. Políticas da memória na criação dos museus brasileiros. Cadernos de Sociomuseologia, Lisboa, n.19, p.99-120. 2002.
SANTOS, Miriam Sepúlveda dos. Objetos, memória e história: observação e análise de um museu histórico brasileiro. Dados - Revista de Ciências Sociais, Rio de Janeiro, v.35, n.2, p.194-216. 1992.

\section{SCHNITTER, C.}

Le développement du Muséum National d'Histoire Naturelle de Paris au cours de la seconde moitiée du XIXe siècle: 'se transformer ou périr'. Revue d'Histoire des Sciences, Paris, v.49, n.1, p.53-97. 1996.

SCHWARCZ, Lilia Moritz.

O espetáculo das raças: cientistas, instituições e questão racial no Brasil, 1870-1930. São Paulo: Companhia das Letras. 1993.

SCHWARCZ, Lilia Moritz.

O nascimento dos museus brasileiros. In: Miceli, Sérgio. História das ciências sociais no Brasil. São Paulo: Vértice; Idesp. 1989.

SILVA, Cristina Maria de Souza e. Pesquisa de público em museus e instituições abertas à visitação: fundamentos e metodologia. Dissertação (Mestrado) Universidade Federal do Rio de Janeiro, Rio de Janeiro. 1989.

STUDART, Denise C. Pesquisa do visitante sobre exposições planejadas para o público infantil em museus na Inglaterra. Comunicação apresentada na Conferência Anual do Comitê para a Educação e Ação Cultural, do Conselho Internacional de Museus, 1997. Rio de Janeiro. 1997.

STUDART, Denise Coelho; ALMEIDA, Adriana Mortara; VALENTE, Maria Esther.

Pesquisa de público em museus:

desenvolvimento e perspectivas. In: Gouvêa,

G.; Marandino, M.; Leal, M.C. (Org.). A construção do caráter social dos museus de ciência. Rio de Janeiro: Faperj; Access. p.129-157. 2003.

TEIXEIRA COELHO, J.

Dicionário crítico de política cultural. São Paulo: Iluminuras; Fapesp. 1997.

TYLER, Ralph W.

Basic principles of curriculum and instruction. Chicago: University of Chicago. 1949.

UFRJ.

Museu Nacional. Escritório Técnico Científico. Projeto da nova exposição do Museu Nacional/UFRJ. Relatório de Atividades, v.2: Conceito. Rio de Janeiro: Museu Nacional; CNPq; UFRJ. Disponível em: http://www.ppgas museu.etc.br/pne2003/pdf/ETC-MN-2002 Conceito_(parcial_FundamentacaoConceitual).pdf. Acesso em: 8 set. 2010.2002. 
VALENTE, Maria Esther

Museus de ciência e tecnologia no Brasil: uma história da museologia entre as décadas de 1950 e 1970. Tese (Doutorado) - Instituto de Geociências, Universidade Estadual de Campinas, Campinas. 2009.

VALENTE, Maria Esther.

Educação em museus: o público de hoje no museu de ontem. Dissertação (Mestrado) Departamento de Educação, Pontifícia Universidade Católica do Rio de Janeiro, Rio de Janeiro. 1995.
VAN PRAET, Michel; DÉMARET, Héléne; DROUIN, Jean-M arc.

L'esprit du lieu, un concept muséologique. In: Eidelman, Jacqueline; Van Präet, Michel (Org.). La muséologie des sciences et ses publics: regards croisées sur la Grande Galerie de I'Évolution du Muséum National d'Histoire Naturelle. Paris: Presses Universitaires de France. p.15-29. 2000.

VIEIRA, Maria Elvira Melo.

Um olhar vassalo: perfil do público na mostra da pintura francesa do Museu de Arte de São Paulo. Dissertação (M estrado) - Instituto de Psicologia, Universidade de São Paulo, São Paulo. 1997.

\section{uuuUUU}

